\title{
Zero net livelihood degradation - the quest for a multidimensional protocol to combat desertification
}

\author{
Marcos H. Easdale \\ Instituto Nacional de Tecnología Agropecuaria (INTA), EEA Bariloche, Área de Desarrollo Rural, \\ Av. Modesta Victoria 4450, 8400 Bariloche, Río Negro, Argentina \\ Correspondence to: Marcos H. Easdale (easdale.marcos@inta.gob.ar)
}

Received: 26 October 2015 - Published in SOIL Discuss.: 10 November 2015

Accepted: 24 March 2016 - Published: 14 April 2016

\begin{abstract}
The concept of Zero Net Land Degradation was recently proposed as the basis for a future protocol for the United Nations Convention to Combat Desertification to reduce global dryland degradation. It aims at reducing the rate of land degradation and increasing the rate of restoration of already degraded land. Whereas there is recognition of the socio-economic contexts that underlie degradation processes, there is a narrow focus on land and soil as the end core that needs to be protected. In particular, there is an essential human dimension to the sustainability of drylands that should be adequately tackled. In order to provide a wider perspective of the zero net degradation in drylands, I suggest considering the different livelihoods of rural households as a framework that encompasses the multidimensional perspective of desertification as a complex social-ecological problem. The scientific community must develop and apply the zero net livelihood degradation as an enhanced protocol to combat desertification that should foster sustainable livelihood outcomes rather than only sustainable land practices or soil management.
\end{abstract}

\section{Introduction}

Land degradation has a profound impact on societies and natural resources worldwide, and it is the most challenging environmental problem in drylands (MEA, 2005). The Rio+20 conference held in Brazil in 2012 agreed on the goal of a land-degradation-neutral world (LDN). It aims at reducing the rate of land degradation and increasing the rate of restoration of already degraded land. This followed a proposal for a goal of Zero Net Land Degradation (ZNLD) made by the United Nations Convention to Combat Desertification secretariat (UNCCD, 2012). Then, the Conference of the Parties of the UNCCD established an intergovernmental working group to examine all the available options to achieve LDN in drylands (Grainger, 2015). Notwithstanding the institutional processes of the UNCCD needed to formally adopt this framework, the concept has already gained consensus as a proposal for a new global protocol to orient the implementation of policies to combat desertification in drylands (Stavi and Lal, 2015). The piecemeal political approach that has prevailed in international desertification legislation should be overcome by a more explicit focus on soil ecosystems and degradation processes (Stringer, 2008).

As a goal to be achieved by 2030, the concept of ZNLD proposes that the extent of global degraded lands will decrease or at least remain stable. To this end, the rate of global land degradation should not exceed that of land restoration, which should consider not only agricultural landscapes but also natural and semi-natural lands that do not necessarily generate direct economic revenues (Stavi and Lal, 2015). Whereas there is recognition of the socio-economic contexts that underlie degradation processes, there is a narrow focus on land and soil as the end core that needs to be protected in drylands. Hence, the significance of sustainable land practices and soil management and the need for coordination actions across scales to monitor and restore lands are emphasized (Salvati et al., 2013). The aim of this paper is to propose an enhanced perspective of the zero net degradation in drylands, by considering the different livelihoods of rural households, which I call the zero net livelihood degradation. This 
proposal encompasses the multidimensional perspective of desertification as a complex social-ecological problem.

\section{Desertification as a complex social-ecological problem}

One of the main academic consensuses over the last decade is that desertification is a complex problem that needs to be tackled by the integration of social and ecological dynamics (e.g. Reynolds and Stafford Smith, 2002; MEA, 2005). Drylands are linked human-environmental, also called socialecological, systems, which means that we require rigorous approaches of complex, multivariable, nonlinear, cross-scale and changing systems (e.g. Reynolds et al., 2007). This integral perspective gave rise to many theoretical discussions and a concomitant development of conceptual frameworks aimed at helping to orient research studies and decision making (e.g. Ostrom, 2007; Chapin et al., 2009).

Notwithstanding this undoubted and promising scientific progress, the transition from discipline-based perspectives towards the emergence of more integral approaches (e.g. sustainability science; Clark and Dickson, 2003) is a complex social process in itself and takes time. Desertification is not an exception, and different theoretical and methodological issues are still under debate (e.g. Thomas, 1997; Verón et al., 2006; Vogt et al., 2011). Research contributions to biophysical degradation assessments (e.g. Cerdà and Lavee, 1999; Cerdà, 2002; Xie et al., 2015; Vieira et al., 2015) and monitoring of desertification processes (e.g. Wang et al., 2013; Bai et al., 2013; Xu and Zhang, 2014) date back to recent decades. However, socio-economic issues still have scant links with the core of biophysical science (Barbero-Sierra et al., 2015; Torres et al., 2015). A step towards an integrated framework to combat desertification was recently proposed in the "Dryland Development Paradigm" (Reynolds et al., 2007) to help understand linked social-ecological systems in drylands. These regions are characterized by a unique set of features that should be taken into account to structure the analysis of change (Reynolds et al., 2007), and for the development of an integrated global monitoring and assessment (Reynolds et al., 2011). In particular, seven features were identified as causally linked in developing a desert syndrome (Stafford Smith, 2008). Lately, a co-evolutionary process between global political, social and economic drivers and local system changes in arid rangelands complemented the perspective on the desert syndrome (Easdale and Domptail, 2014). These concurrent frameworks demonstrate the recent efforts to better conceptualize desertification, from the perspective of a complex social-ecological process across scales.

\section{Zero Net Land Degradation: bases and challenges for a new protocol}

The concept of ZNLD proposes that the extent of global degraded lands in arid, semi-arid, and dry sub-humid areas will decrease or at least remain stable for the next 15 years. This approach is based on three key premises (Chasek et al., 2015): (i) the goal to completely prevent further degradation is too ambitious and the focus should be rather on reducing its rate, (ii) the global land that is already degraded has reached a warning spatial extent of almost $20 \%$ (MEA, 2005), and (iii) the provision of ecosystem services (in particular biological productivity) from already degraded lands can be recovered or restored. To this end, there are a series of scientific and political challenges and opportunities for the implementation of a ZNLD protocol in drylands worldwide (Gnacadja, 2015).

The main identified scientific challenges relate to monitoring and management practices (Stavi and Lal, 2015). One of the highest priorities is producing a global assessment of land and soil degradation, which involves measurements, monitoring indicators and data, and verification of land status and effectiveness of restoration measures at different spatial and temporal scales (Grainger, 2015; Stavi and Lal, 2015). On the other hand, the main identified implementation challenges relate to political consensus and support, awareness and empowerment of local communities, prescribing relevant management practices and financial resources and supporting mechanisms (Chasek et al., 2015; Stavi and Lal, 2015). Finally, some critiques and pitfalls from existing environmental trading mechanisms are highlighted in order to develop recommendations for future ZNLD policies (Tal, 2015). Some of the main issues include the unreliability of trades aimed at restoring ecosystems, the need for clear and quantifiable units of measure, accurate definitions of spatial and temporal equivalences given land heterogeneity, and the need to consider delayed benefits and difficulties to ensure the future benefits of present land restoration efforts (Tal, 2015).

\section{Sustainable livelihoods approach}

The sustainable livelihoods approach is a multidisciplinary framework that organizes in a hierarchical manner the information related to how different people in different places live. The approach is people-centred and emphasizes multiple resources, actors, strategies, and outcomes (Scoones, 2009), with strong opportunities for scientific interdisciplinary integration.

The sustainable livelihoods framework links inputs as measured by the access to a range of livelihood resources and outputs such as livelihood strategies (Scoones, 2009). Given a particular context (i.e. political, historical, agroecological and socio-economic), the focus is to understand what combination of livelihood resources, which are designated as a metaphor with the terms "capitals" or "assets", 
result in the ability to deliver a combination of livelihood strategies such as agricultural intensification (Adams and Mortimore, 1997), livelihood diversification (Ellis and Allison, 2004; Easdale and Rosso, 2010; Tesfaye et al., 2011), or even non-agricultural activities as tourism (Iorio and Corsale, 2010). Hence, the strongest focuses have been oriented towards the so-called asset pentagon (i.e. where each vertex depicts a livelihood resource), with relevant discussions about how assets can be combined, substituted, and switched to develop different portfolios for different farmers, in different places and under different environmental or social changes (Scoones, 2009).

The five most frequent types of capitals that comprise the vertices of that pentagon are the natural, human, social, manufactured, and financial capitals (Ekins et al., 2003; Davies et al., 2008). Natural capital is a metaphor to indicate the importance of elements of nature to human wellbeing (Daly, 1994). It includes environmental functions and services, which have been classified into four categories (De Groot et al., 2002): regulation, production, habitat, and information functions. Human capital comprises all individuals' capabilities important for the pursuit of any livelihood strategy (i.e. knowledge, skills, labour capacities), while social capital relates to the networks and organizations that coordinate individual contributions and actions. Manufactured capital comprises material or physical goods typically involved in a production process (i.e. machineries, tools, reproductive animals), while financial capital includes monetary assets (or equivalent), which contribute both to the production process and household economy (more information in Scoones, 1998; Ekins et al., 2003).

\section{A step towards a multidimensional protocol to combat desertification}

The aim of reducing the rate of land degradation and increasing the rate of restoration of already degraded land should not be promoted with a side effect such as increasing degradation of other human and social livelihoods. There is an assumption that the reduction of the rate of land degradation and restoration of already degraded lands are the main options at hand to enhance the wellbeing of local poor people, as well as the global community in the long term. However, there is an essential human dimension to the sustainability of trades in native products from drylands that needs to be adequately tackled (Walsh and Douglas, 2011). Concurring with this statement, the question then is the following: which are the most effective policy interventions and where should they focus? In this direction, I propose that ecosystem conservation and restoration debates in ZNLD policies should be integrated into the concept of food sovereignty, where nature matters in terms of autonomous food and local farming systems (Altieri and Toledo, 2011; Wittman and Desmarais, 2011), by strengthening the linkage between local communi- ties and nature (e.g. Beyene, 2015; Assefa and Hans-Rudolf, 2015).

Sustainable rangeland management cannot be achieved if sustainable livelihoods of rangeland users are neglected (Gharibvand et al., 2015). Interventions should be oriented towards the enhancement of social-ecological resilience and adaptive capacity of local communities in drylands (e.g. Davies et al., 2008; Tittonell, 2014), by supporting the diversity of rural livelihoods, which may be much more efficient than a narrow focus only on sustainable land practices and soil management. For instance, this wider perspective should avoid the erosion of traditional knowledge and weakening of local institutions (Linstädter et al., 2013; Schmidt and Pearson, 2016) in order to prevent crossing over human critical thresholds that may drive future land degradation processes (Easdale and López, 2014). Local ecological knowledge, the social values, and productive logics involving mobile pastoralism with informal rules for management, local breeding, or common property are at the core of sustainable land management in many drylands (e.g. FernándezGiménez, 2000; Rohde et al., 2006). However, they were frequently seen as unsustainable from the perspective of a western mindset (e.g. Hardin, 1968) that proposes radical shifts in land policies, technologies, and innovations (Schmidt and Pearson, 2016), which are said to be more sustainable since they are based on science (Easdale and Domptail, 2014). Then, the statement that land-degraded management practices need to be replaced with ones that conserve soils hides the assumptions that support this argument, which regards the kind of knowledge that defines indicators, data, and sustainable practices.

A livelihood is said to be sustainable "when it can cope with and recover from stresses and shocks and maintain or enhance its capabilities and assets both now and in the future, while not undermining the natural resource base" (Chambers and Conway, 1992). This means that desertification combat should not just be directed to sustainable management practices aimed at restoring degraded lands such as inorganic and organic-soil amendments or at reducing the rates of current soil erosion (e.g. by using straw mulching and crop residues) and rangeland degradation (e.g. by controlling livestock pressure to prevent overstocking). The dominant approaches of many suggested practices are still purely biophysical (e.g. García-Orenes et al., 2012; Weyers and Spokas, 2014; Sadeghi et al., 2015; Cerdà et al., 2015). However, the livelihood approach provides the perspective that natural resource degradation should be tackled in a wider manner than only a cause-and-effect logic due to a linear ecological process (Gharibvand et al., 2015). Other socioeconomic direct and ultimate drivers should also be included in order to orient interventions adequately (Easdale and Domptail, 2014).

Policies aimed at supporting the diversity of livelihood resources can serve as a portfolio to cope with or to offset further land degradation and even to restore degraded land. For 
instance, different livelihood strategies, such as income diversification and social networks involving partnership to obtain better prices from associated sales, served as decoupling mechanisms between smallholder household income and the impact of drought on their livestock systems (Easdale and Rosso, 2010). Additional off-farm income can favour conservative management, release pressure on natural resources, and promote reinvestment or complement livestock expenditures while natural resources recover (Kilic et al., 2009). Studies on the influence of the diversity of rural livelihoods on soil fertility status and its spatial variation shed light in the promotion of differentiated technological innovations to address the problem of poor productivity of smallholder farms (Tittonell et al., 2010). The identification of socio-economic variables associated with environmental conditions can lead to a long-term reduction in land sensitivity to degradation (Salvati and Carlucci, 2014). Then, tackling different household livelihood strategies is thus necessary not only to target agricultural innovations but also to understand how the specific objectives, logics, and endowments of different household types affect resource allocation and management practices (Tittonell et al., 2010).

\section{Conclusions}

The concept of Zero Net Land Degradation proposes the basis for a future protocol to reduce global dryland degradation. However, there is an essential human dimension to the sustainability of drylands that should be adequately tackled. In order to provide a wider perspective of the zero net degradation in drylands, I suggest considering the different livelihoods of rural households as a proposal that encompasses the multidimensional perspective of desertification as a complex social-ecological problem. Zero net livelihood degradation as a new UNCCD protocol to combat desertification should foster sustainable livelihood outcomes rather than only sustainable land practices or soil management.

Acknowledgements. I acknowledge the financial support provided by INTA (PATNOR-1281103).

Edited by: F. García-Orenes

\section{References}

Adams, W. M. and Mortimore, M. J.: Agricultural intensification and flexibility in the Nigerian Sahel, Geographical J., 163, 150160, doi:10.2307/3060178, 1997.

Altieri, M. A. and Toledo, V. M.: The agroecological revolution in Latin America: rescuing nature, ensuring food sovereignty and empowering peasants. J. Peasant Stud., 38, 587-612, doi:10.1080/03066150.2011.582947, 2011.

Assefa, E. and Hans-Rudolf, B.: Farmers' Perception of Land Degradation and Traditional Knowledge in South- ern Ethiopia-Resilience and Stability, Land Degrad. Dev., doi:10.1002/ldr.2364, in press, 2015.

Bai, X.-Y., Wang, S.-J., and Xiong, K.-N.: Assessing spatialtemporal evolution processes of karst rocky desertification land: Indications for restoration strategies, Land Degrad. Dev., 24, 4756, doi:10.1002/ldr.1102, 2013.

Barbero-Sierra, C., Marques, M. J., Ruiz-Pérez, M., Escadafal, R., and Exbrayat, W.: How is desertification research addressed in Spain? Land versus soil approaches, Land Degrad. Dev., 26, 423-432, doi:10.1002/ldr.2344, 2015.

Beyene, F.: Incentives and Challenges in Community-Based Rangeland Management: Evidence from Eastern Ethiopia, Land Degrad. Dev., 26, 502-509, doi:10.1002/ldr.2340, 2015.

Cerdà, A.: The effect of season and parent material on water erosion on highly eroded soils in eastern Spain, J. Arid Environ., 52, 319337, doi:10.1006/jare.2002.1009, 2002.

Cerdà, A. and Lavee, H.: The effect of grazing on soil and water losses under arid and mediterranean climates. Implications for desertification, Pirineos, 153-154, 159-174, doi:10.3989/pirineos.1999.v153-154.111, 1999.

Cerdà, A., González-Pelayo, O., Giménez-Morera, A., Jordán, A., Pereira, P., Novara, A., Brevik, E. C., Prosdocimi, M., Mahmoodabadi, M., Keesstra, S., García-Orenes, F., and Ritsema, C.: The use of barley straw residues to avoid high erosion and runoff rates on persimmon plantations in Eastern Spain under low frequency - high magnitude simulated rainfall events, Soil Res., 54, 154165, doi:10.1071/SR15092, 2015.

Chambers, R. and Conway, G.: Sustainable rural livelihoods: practical concepts for the 21 st century, Institute of Development Studies, UK, 29 pp., 1992.

Chapin III, F. S., Kofinas, G. P., and Folke, C.: Principles of ecosystem stewardship: resilience-based natural resource management in a changing world, Springer, New York, 22-37, 2009.

Chasek, P., Safriel, U., Shikongo, S., and Fuhrman, V. F.: Operationalizing Zero Net Land Degradation: The next stage in international efforts to combat desertification?, J. Arid Environ., 112, 5-13, doi:10.1016/j.jaridenv.2014.05.020, 2015.

Clark, W. C. and Dickson, N. M.: Sustainability science: the emerging research program, P. Natl. Acad. Sci., 100, 8059-8061, doi:10.1073/pnas.1231333100, 2003.

Daly, H.: Operationalizing sustainable development by investing in natural capital, in: Investing in Natural Capital: The ecological economics approach to sustainability, edited by: Jansson, A. M., Hammer, M., Folke, C., and Costanza, R., Island Press, Washington, D.C., USA, 22-37, 1994.

Davies, J., White, J., Wright, A., Maru, Y., and LaFlamme, M.: Applying the sustainable livelihoods approach in Australian desert Aboriginal development, Rangeland J., 30, 55-65, doi:10.1071/RJ07038, 2008.

De Groot, R. S., Wilson, M. A., and Boumans, R. M.: A typology for the classification, description and valuation of ecosystem functions, goods and services, Ecol. Econ., 41, 393-408, doi:10.1016/S0921-8009(02)00089-7, 2002.

Easdale, M. H. and Domptail, S. E.: Fate can be changed! Arid rangelands in a globalizing world- A complementary co-evolutionary perspective on the current 'desert syndrome', J. Arid Environ., 100-101, 52-62, doi:10.1016/j.jaridenv.2013.10.009, 2014. 
Easdale, M. H. and López, D. R.: Sustainable livelihood approach from the lens of the state-and-transition model: an integrated model for social-ecological research and management, Resilience and Development: Mobilizing for Transformation, Report Session 111 - Agroecological Transition and Resilience, Montpellier, France, 16-17, 2014.

Easdale, M. H. and Rosso, H.: Dealing with drought: social implications of different smallholder survival strategies in semi-arid rangelands of Northern Patagonia, Argentina, Rangeland J., 32, 247-255, doi:10.1071/RJ09071, 2010.

Ekins, P., Simon, S., Deutsch, L., Folke, C., and De Groot, R.: A framework for the practical application of the concepts of critical natural capital and strong sustainability, Ecol. Econo., 44, 165185, doi:10.1016/S0921-8009(02)00272-0, 2003.

Ellis, F. and Allison, E.: Livelihood diversification and natural resource access, Overseas Development Group, University of East Anglia, FAO, Rome, 37 pp., 2004.

Fernández-Giménez, M. E.: The role of Mongolian nomadic pastoralists' ecological knowledge in rangeland management, Ecol. Appl., 10, 1318-1326, doi:10.2307/2641287, 2000.

García-Orenes, F., Roldán, A., Mataix-Solera, J., Cerdà, A., Campoy, M., Arcenegui, V., and Caravaca, F.: Soil structural stability and erosion rates influenced by agricultural management practices in a semi-arid Mediterranean agro-ecosystem, Soil Use Manage., 28, 571-579, doi:10.1111/j.1475-2743.2012.00451.x, 2012.

Gharibvand, H. K., Azadi, H., and Witlox, F.: Exploring appropriate livelihood alternatives for sustainable rangeland management, Rangeland J., 37, 345-356, doi:10.1071/RJ15027, 2015.

Gnacadja, L.: New challenges in science and policies to combat desertification, J. Arid Environ., 112, 1-4, doi:10.1016/j.jaridenv.2014.10.010, 2015.

Grainger, A.: Is Land Degradation Neutrality feasible in dry areas?, J. Arid Environ., 112, 14-24, doi:10.1016/j.jaridenv.2014.05.014, 2015.

Hardin, G.: The tragedy of the commons, Science, 162, 1243-1248, doi:10.1126/science.162.3859.1243, 1968.

Iorio, M. and Corsale, A.: Rural tourism and livelihood strategies in Romania, J. Rural Stud., 26, 152-162, doi:10.1016/j.jrurstud.2009.10.006, 2010.

Kilic, T., Carletto, C., Miluka, J., and Savastano, S.: Rural nonfarm income and its impact on agriculture: evidence from Albania, Agricult. Econ., 40, 139-160, doi:10.1111/j.15740862.2009.00366.x, 2009.

Linstädter, A., Kemmerling, B., Baumann, G., and Kirscht, H.: The importance of being reliable-local ecological knowledge and management of forage plants in a dryland pastoral system (Morocco), J. Arid Environ., 95, 30-40, doi:10.1016/j.jaridenv.2013.03.008, 2013.

MEA - Millennium Ecosystem Assessment: Ecosystems and human well-being: Desertification synthesis, World Resources Institute, Washington, D.C., 36 pp., 2005.

Ostrom, E.: A diagnostic approach for going beyond panaceas, P. Natl. Acad. Sci., 104, 15181-15187, doi:10.1073/pnas.0702288104, 2007.

Reynolds, J. F. and Stafford Smith, D. M.: Global desertification: Do humans cause deserts?, Dahlem University Press, Berlin, 430 pp., 2002.
Reynolds, J. F., Stafford Smith, D. M., Lambín, E. F., Turner II, B. L., Mortimore, M., Batterbury, S. P. J., Downing, T. E., Dowlatabadi, H., Fernández, R., Herrick, J. E., HuberSannwald, E., Jiang, H., Leemans, R., Lynam, T., Maestre, F. T., Ayrza, M., and Walker, B.: Global desertification: building a science for dryland development, Science, 316, 847-851, doi:10.1126/science.1131634, 2007.

Reynolds, J. F., Grainger, A., Stafford Smith, D. M., Bastin, G., Garcia-Barrios, L., Fernández, R. J., Janssen, M. A., Jürgens, N., Scholes, R. J., Veldkamp, A., Verstraete, M. M., Von Maltitz, G., and Zdruli, P.: Scientific concepts for an integrated analysis of desertification, Land Degrad. Dev., 22, 166-183, doi:10.1002/ldr.1104, 2011.

Rohde, R. F., Moleele, N. M., Mphale, M., Allsopp, N., Chanda, R., Hoffman, M. T., Magole, L., and Young, E.: Dynamics of grazing policy and practice: environmental and social impacts in three communal areas of southern Africa, Environ. Sci. Policy, 9, 302-316, doi:10.1016/j.envsci.2005.11.009, 2006.

Sadeghi, S. H. R., Gholami, L., Homaee, M., and Khaledi Darvishan, A.: Reducing sediment concentration and soil loss using organic and inorganic amendments at plot scale, Solid Earth, 6, 445-455, doi:10.5194/se-6-445-2015, 2015.

Salvati, L. and Carlucci, M.: Zero Net Land Degradation in Italy: The role of socioeconomic and agro-forest factors, J. Environ. Manage., 145, 299-306, doi:10.1016/j.jenvman.2014.07.006, 2014.

Salvati, L., Tombolini, I., Perini, L., and Ferrara, A.: Landscape changes and environmental quality: the evolution of land vulnerability and potential resilience to degradation in Italy, Reg. Environ. Change, 13, 1223-1233, doi:10.1007/s10113-013-0437-3, 2013.

Schmidt, M. and Pearson, O.: Pastoral livelihoods under pressure: Ecological, political and socioeconomic transitions in Afar (Ethiopia), J. Arid Environ., 124, 22-30, doi:10.1016/j.jaridenv.2015.07.003, 2016.

Scoones, I.: Sustainable rural livelihoods: a framework for analysis, IDS Working Paper 72, Institue of Development Studies (IDS), Brighton, UK, 22 pp., 1998.

Scoones, I.: Livelihoods perspectives and rural development, J. Peasant Stud., 36, 171-196, doi:10.1080/03066150902820503, 2009.

Stafford Smith, D. M.: The 'desert syndrome' - causally-linked factors that characterise outback Australia, Rangeland J., 30, 3-14, doi:10.1071/RJ07063, 2008.

Stavi, I. and Lal, R.: Achieving zero net land degradation: challenges and opportunities, J. Arid Environ., 112, 44-51, doi:10.1016/j.jaridenv.2014.01.016, 2015.

Stringer, L.: Can the UN Convention to Combat Desertification guide sustainable use of the world's soils?, Front. Ecol. Environ., 6, 138-144, doi:10.1890/070060, 2008.

Tal, A.: The implications of environmental trading mechanisms on a future Zero Net Land Degradation protocol, J. Arid Environ., 112, 25-32, doi:10.1016/j.jaridenv.2014.05.013, 2015.

Tesfaye, Y., Roos, A., Campbell, B. M., and Bohlin, F.: Livelihood strategies and the role of forest income in participatory-managed forests of Dodola area in the bale highlands, southern Ethiopia, Forest Policy Econ., 13, 258-265, doi:10.1016/j.forpol.2011.01.002, 2011. 
Thomas, D. S. G.: Science and the desertification debate, J. Arid Environ., 37, 599-608, doi:10.1006/jare.1997.0293, 1997.

Tittonell, P.: Livelihood strategies, resilience and transformability in African agroecosystems, Agricult. Syst., 126, 3-14, doi:10.1016/j.agsy.2013.10.010, 2014.

Tittonell, P., Muriuki, A., Shepherd, K. D., Mugendi, D., Kaizzi, K. C., Okeyo, J., Verchot, L., Coe, R., and Vanlauwe, B.: The diversity of rural livelihoods and their influence on soil fertility in agricultural systems of East Africa-A typology of smallholder farms, Agricult. Syst., 103, 83-97, doi:10.1016/j.agsy.2009.10.001, 2010.

Torres, L., Abraham, E. M., Rubio, C., Barbero-Sierra, C., and Ruiz-Pérez, M.: Desertification research in Argentina, Land Degrad. Dev., 26, 433-440, doi:10.1002/ldr.2392, 2015.

UNCCD - United Nations Convention to Combat Desertification: Zero Net Land Degradation. A sustainable development goal for Rio +20 . UNCCD Secretariat Policy Brief, UN Convention to Combat Desertification, Bonn, 32 pp., 2012.

Verón, S. R., Paruelo, J. M., and Oesterheld, M.: Assessing desertification, J. Arid Environ., 66, 751-763, doi:10.1016/j.jaridenv.2006.01.021, 2006.

Vieira, R. M. S. P., Tomasella, J., Alvalá, R. C. S., Sestini, M. F., Affonso, A. G., Rodriguez, D. A., Barbosa, A. A., Cunha, A. P. M. A., Valles, G. F., Crepani, E., De Oliveira, S. B. P., De Souza, M. S. B., Calil, P. M., De Carvalho, M. A., Valeriano, D. M., Campello, F. C. B., and Santana, M. O.: Identifying areas susceptible to desertification in the Brazilian northeast, Solid Earth, 6, 347-360, doi:10.5194/se-6-347-2015, 2015.
Vogt, J. V., Safriel, U., Von Maltitz, G., Sokona, Y., Zougmore, R., Bastin, G., and Hill, J.: Monitoring and assessment of land degradation and desertification: Towards new conceptual and integrated approaches, Land Degrad., Dev., 22, 150-165, doi:10.1002/ldr.1075, 2011.

Walsh, F. and Douglas, J.: No bush foods without people: the essential human dimension to the sustainability of trade in native plant products from desert Australia, Rangeland J., 33, 395-416, doi:10.1071/RJ11028, 2011.

Wang, T., Yan, C. Z., Song, X., and Li, S.: Landsat images reveal trends in the aeolian desertification in a source area for sand and dust storms in china's alashan plateau (1975-2007), Land Degrad. Dev., 24, 422-429, doi:10.1002/ldr.1138, 2013.

Weyers, S. L. and Spokas, K. A.: Crop residue decomposition in Minnesota biochar-amended plots, Solid Earth, 5, 499-507, doi:10.5194/se-5-499-2014, 2014.

Wittman, H. and Desmarais, A. A.: Food sovereignty: reconnecting food, nature \& community, Pambazuka Press, Oxford, 212 pp., 2011.

Xie, L. W., Zhong, J., Chen, F. F., Cao, F. X., Li, J. J., and Wu, L. C.: Evaluation of soil ferti-lity in the succession of karst rocky desertification using principal component analysis, Solid Earth, 6, 515-524, doi:10.5194/se-6-515-2015, 2015.

$\mathrm{Xu}$, E. Q. and Zhang, H. Q.: Characterization and interaction of driving factors in karst rocky desertification: A case study from Changshun, China, Solid Earth, 5, 1329-1340, doi:10.5194/se-51329-2014, 2014. 